\title{
Epidemiological Study of Patients of Road Traffic Injuries Attending Emergency Department of a Trauma Center in New Delhi
}

\author{
Puneet Misra, Anindo Majumdar', Mahesh Chandra Misra², Shashi Kant, Sanjeev Kumar Gupta, Amit Gupta ${ }^{3}$, Subodh Kumar ${ }^{3}$ \\ Centre for Community Medicine, All India Institute of Medical Sciences, New Delhi, ${ }^{1}$ Department of Community and Family Medicine, All India Institute of Medical Sciences, \\ Bhopal, Madhya Pradesh, ${ }^{2}$ All India Institute of Medical Sciences, ${ }^{3}$ Division of Trauma Surgery and Critical Care, Jai Prakash Narayan Apex Trauma Centre, All India \\ Institute of Medical Sciences, New Delhi, India
}

\section{Abstract}

Background and Aims: There is paucity of data regarding some of the lesser known contextual and epidemiological factors with respect to road traffic injuries (RTIs). The objective was to study the epidemiological profile of RTI victims attending an emergency department of a tertiary care trauma center. Methods: The present study was a hospital-based cross-sectional study conducted in the emergency department of a tertiary care trauma center in New Delhi. All patients of RTI attending the emergency department during the designated data collection days were included in the study. Patients brought dead were excluded from the study. A semi-structured interview schedule was developed for collecting data on various domains such as sociodemographic characteristics, vehicle-related factors, accident site-related factors, personal protection measures, contextual factors, and prehospital care-related factors. Results: A total of 984 patients and informants were approached and finally data of 900 participants were analyzed after excluding those who refused participation and those for whom incomplete data were available. Out of 900 RTI victims, 756 were male (84.0\%) and $144(16.0 \%)$ were female. Mean age of the victims was 32.7 years. Most of the victims, i.e., 377 out of 900 (41.9\%) were occupants rather than drivers. Majority of victim's vehicle meeting accidents were motorized two-wheelers (53.4\%), and majority of the colliding vehicle was a four-wheeler (39.3\%). Helmet use was found to be low (63.3\%), but seat belt use was particularly low (32.4\%). Most accidents (28\%) happened between midnight and 6 A.M. More than half of the victims were in a hurry on the day of the accident. An ambulance was used to transport the victims in only $14.6 \%$ cases. Conclusion: In road traffic accidents some lesser known epidemiological data were generated that may be useful in defining preventive measures.

Keywords: Epidemiology, India, injuries, road, traffic

\section{INTRODUCTION}

Road traffic injuries (RTIs) have become an important public health issue along with communicable and noncommunicable diseases globally and in India. For instance, in India, in the year 2015 , a total of 464,674 road traffic accidents were reported, leading to 482,389 injuries and 148,707 deaths. ${ }^{[1]}$ An analysis of cause of death from 2002 to 2011 in a population $\geq 15$ years of age at Ballabgarh showed that $14.4 \%$ of all deaths were due to external causes and RTIs consisted of almost one-third of all deaths due to external causes. ${ }^{[2]}$ Similarly, in another study in 2005, out of the total number of unintentional injury deaths, $29 \%$ deaths were reported to be due to RTIs. ${ }^{[3]}$ In Delhi alone, there were a total of 8085 road traffic accident cases, with 1622 deaths in 2015. ${ }^{[1]}$

\begin{tabular}{|l|l|}
\hline \multicolumn{3}{c|}{ Access this article online } \\
\hline Quick Response Code: & Website: \\
& www.ijccm.org \\
\hline
\end{tabular}

There is still a lack of proper documentation of RTIs in India, particularly with reference to the lesser studied epidemiological and contextual factors. Factors such as age, gender, and urban-rural distribution, type of vehicle, type of roads used, time distribution of accidents, precautionary measures taken and cause of accidents, mainly over speeding, careless driving and poor weather conditions have been consistently recorded in studies. Whereas, factors such as opposite colliding vehicle, sitting capacity of vehicles, site of accident, perception of the

Address for correspondence: Dr. Puneet Misra, Centre for Community Medicine, Old OT Block, All India Institute of Medical Sciences, New Delhi, India. E-mail: doctormisra@gmail.com

This is an open access article distributed under the terms of the Creative Commons Attribution-NonCommercial-ShareAlike 3.0 License, which allows others to remix, tweak, and build upon the work non-commercially, as long as the author is credited and the new creations are licensed under the identical terms.

For reprints contact: reprints@medknow.com

How to cite this article: Misra P, Majumdar A, Misra MC, Kant S, Gupta SK, Gupta A, et al. Epidemiological study of patients of road traffic injuries attending emergency department of a trauma center in New Delhi. Indian J Crit Care Med 2017;21:678-83. 
victims, psychological factors and prehospital care-related factors have been explored less, with only a handful of studies reporting these variables. ${ }^{[1,4]}$

To develop efficient road safety mechanisms and to effectively address prehospital care in RTIs, epidemiological data generated out of local studies with robust methodologies are extremely important. As per our knowledge, there are limited studies in India, especially from North India, about the role of the present day conflicts (bothered from traffic jam, quarrel, increased speed, competition with other vehicles, etc.) that culminate in accidents. There is still lesser count of literature about contextual conditions on the day of accident. This study was thus contemplated to throw some light on these less-studied factors in addition to the oft-studied ones, to fill the gap in our knowledge regarding RTIs. Objectives of the present study were to study the epidemiological profile of road traffic injury victims attending an emergency department of a tertiary care trauma center attached to a medical college.

\section{Methods}

\section{Study setting}

The present study was a hospital-based cross-sectional study conducted in the emergency department of a tertiary care trauma center in New Delhi. This tertiary care center had at the time of conduct of the study, five operation theaters, 152 inpatient beds and 30 casualty beds (including 26 Intensive Care Unit beds). In addition to admitting patients directly, this center also acts as a referral hospital for many zonal public hospitals and satellite trauma centres. On an average, about 900-1000 trauma victims attended the emergency department of the tertiary care trauma center in a week, out of which, about $500-600$ of them being RTI patients. Out of this total number of RTI cases, around 40-50 were admitted to the wards per week. Figure 1 depicts the care pathway and management protocol for patients attending the emergency department of the tertiary care trauma center.

\section{Study period, sample size, and sampling strategy}

The present study was conducted during the year 2011, with data collection done for 15, 20, and 20 days in May, August, and December, respectively. This calculation was based on

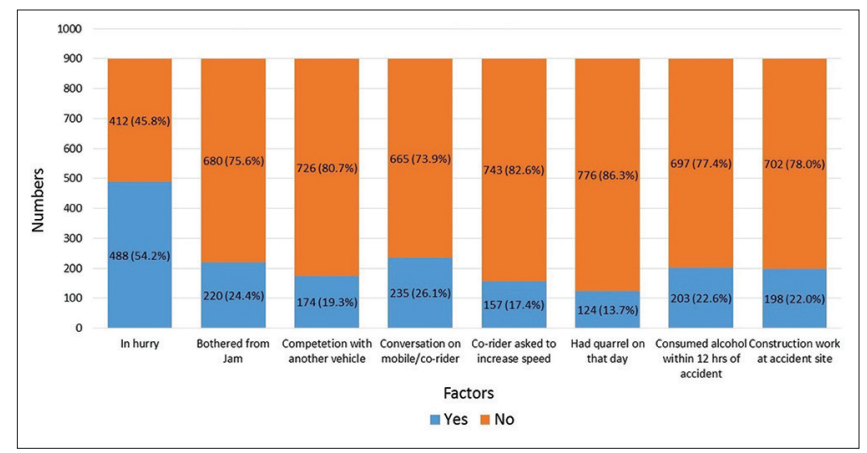

Figure 1: Distribution of some of the accident-related contextual factors among the road traffic injury victims $(n=900)$ sample size requirements, the idea of negating the effect of seasonal variation and feasibility issues.

\section{Inclusion and exclusion criteria}

All patients of RTI attending the emergency of the tertiary care trauma center, during the data collection days in the above-mentioned months were included in the study. Patients brought dead were excluded from the study.

\section{Data sources and study tool}

Data were collected both from records and by interviewing participants. A semi-structured interview schedule was developed. The same was used for collecting data on various domains such as sociodemographic characteristics, vehicle-related factors, accident site-related factors, personal protection measures, contextual factors, and prehospital care-related factors. The interview schedule was translated in Hindi (local language) and back-translated to English to ensure consistency. Pretesting of the questionnaire was done in the casualty of Safdarjung hospital in New Delhi.

The color coding of patients attending the emergency department for prioritizing treatment is shown in Figure 1. Exit interviews were conducted for a green coded patient, with the next interview conducted for the patient available at the exit, after completion of the previous interview. RTI was defined as "any injury due to crashes originating, terminating or involving a vehicle partially or fully on public highway." [5] For cases admitted, all those admitted within the last $24 \mathrm{~h}$ were interviewed. In case the RTI victim was unconscious, the attendant with closest blood relation available at the time of data collection was interviewed. Some of the information such as vehicle involved in accident, colliding vehicle, time of accident, and consumption of alcohol was routinely collected and stored in the existing database at the tertiary care trauma centre, which was also collected later to fill any information missed during interviews and was also used to cross-check the data collected during interviews. About 15 green coded patients were interviewed each day, and each interview took about 15-20 min. Around six to seven admitted cases (yellow/ red coded) were interviewed per day.

\section{Ethical considerations}

Written informed consent was obtained from all participants and legally authorized representatives before including them in the study. The study was approved by Ethics committee of AIIMS, New Delhi.

\section{Methods to reduce willful misrepresentation}

The participants were assured that the information provided by them will be kept confidential and will not be shared with anybody outside the research team, including the police.

\section{Statistical analysis}

Data were entered into Epi info (Centers for Disease Control and Prevention, Atlanta, GA, USA) version 3.5.1. Internal consistency and validity of the data were ascertained by fully checking the data at the time of data entry and then random 
re-checking after completion of data entry. Data cleaning was done after which, the analysis was done using Statistical Package for Social Sciences version 17.0 (SPSS Inc., Chicago, IL, USA). Proportions and means were calculated.

\section{RESULTS}

A total of 984 participants were approached, out of which, 928 could be interviewed (response rate of 94.3\%). Further, complete information for 28 participants could not be collected. Hence, finally, data from 900 participants were included in the analysis. For major accidents, most of the respondents, i.e., 136 out of $217(62.7 \%)$ were patients themselves, whereas for minor accidents, almost all, i.e., 682 out of 683 (99.9\%) respondents were patients themselves. Respondents other than patients were relatives or police.

Out of 900 RTI victims, 756 were male (84.0\%) and $144(16.0 \%)$ were female. The mean age of the victims was 32.7 years, range being 1 year to 97 years. Majority $(47.4 \%)$ of the victims belonged to the age group of 16-30 years, were currently married and lived with their families [Table 1]. Most of the participants had completed secondary school and were currently employed.

Table 2 shows the distribution of the study participants according to personal protection, vehicle and accident

\begin{tabular}{|c|c|c|}
\hline $\begin{array}{l}\text { Sociodemographic } \\
\text { factor }\end{array}$ & Category & Frequency (\%) \\
\hline \multirow[t]{5}{*}{ Age (years) } & $1-15$ & $74(8.2)$ \\
\hline & $16-30$ & $427(47.4)$ \\
\hline & $31-45$ & $243(27.0)$ \\
\hline & $46-60$ & $115(12.8)$ \\
\hline & $\geq 61$ & $41(4.6)$ \\
\hline \multirow[t]{2}{*}{ Sex } & Male & $756(84.0)$ \\
\hline & Female & $144(16.0)$ \\
\hline \multirow[t]{4}{*}{ Marital status } & Unmarried & $304(33.8)$ \\
\hline & Married & $503(55.9)$ \\
\hline & Widow/widower & $77(8.6)$ \\
\hline & Divorced/separated & $16(1.7)$ \\
\hline \multirow[t]{3}{*}{ Living status } & Alone & $279(31.0)$ \\
\hline & With family & $561(62.4)$ \\
\hline & With friends & $60(6.6)$ \\
\hline \multirow[t]{6}{*}{ Education } & Illiterate & $128(14.3)$ \\
\hline & Primary school & $130(14.7)$ \\
\hline & Secondary school & $243(26.9)$ \\
\hline & Higher secondary & $135(15.2)$ \\
\hline & Graduate & $225(25.0)$ \\
\hline & Postgraduate & $36(3.9)$ \\
\hline \multirow[t]{4}{*}{ Occupation } & Unemployed & $74(8.2)$ \\
\hline & Student & $234(26.0)$ \\
\hline & $\begin{array}{l}\text { Employed (unskilled, skilled } \\
\text { and professional work) }\end{array}$ & $573(63.7)$ \\
\hline & Retired & $19(2.1)$ \\
\hline
\end{tabular}

site-related factors. In most of the accidents, participants were occupants (passengers/pillion riders), and the vehicles mostly involved were motorized two-wheelers, with majority of the vehicles having a maximum of two seats. Nearly, $40 \%$ cases, the opposite colliding vehicle was a motorized four wheeler, 54\% accidents took place between 6 A.M. and 6 P.M., and in majority of cases, accidents took place on a straight road. A staggering $85.4 \%$ of participants perceived that the driver of the opposite colliding vehicle was mainly responsible for the accident. A little more than $60 \%$ of the drivers and riders of two-wheelers had worn helmets at the time of accident, whereas, in case of motorized four wheelers, majority did not use seat belts. Almost one-fifth of the drivers in the present study did not possess a driving license during the time of accident.

Table 3 summarizes the distribution of prehospital care-related factors among the study participants. Figure 2 describes in a graphical form, some of the accident-related contextual factors. More than half of the victims were in a hurry at the time of accident. Nearly, one-quarter of the participants had consumed alcohol, were talking to someone on phone/co-rider or were bothered from jam at the time of accident. Out of 900 participants, most of the participants, i.e., $392(43.5 \%)$ reported weather on the day of accident to be hot, while $268(29.7 \%)$ reported it to be cold (data not shown). Other participants remembered the weather to be either rainy or clear. Total distance travelled before accident was reported by $627(69.7 \%$ ) participants to be in the range 0-25 km (data not shown). This was followed by 165 (18.4\%) and $108(11.9 \%)$ participants who had travelled $>50$ and $26-50 \mathrm{~km}$ respectively before meeting the accident. In terms of total distance planned to be travelled on the day of accident, most of the participants,

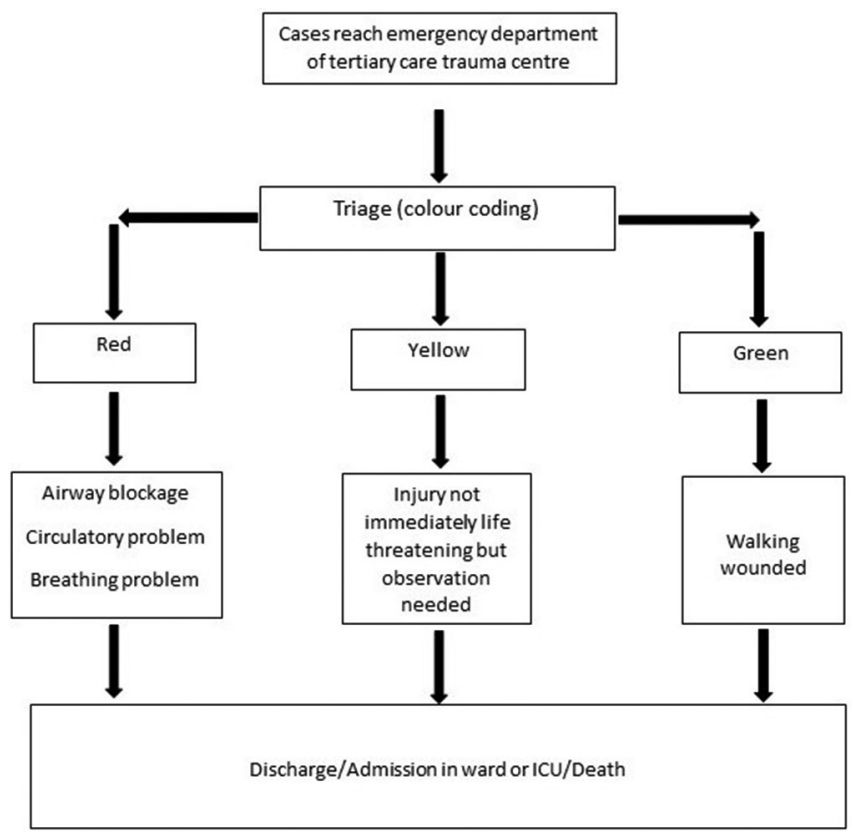

Figure 2: Care pathway and management protocol of patients attending the emergency department of the tertiary care trauma center 


\begin{tabular}{|c|c|c|}
\hline Vehicle/personal protection/accident site-related factor & Category & Number of participants (\%) \\
\hline \multirow[t]{4}{*}{ Role of victim at the time of accident $(n=900)$} & Pedestrian & $179(19.9)$ \\
\hline & Passenger* & $153(17.0)$ \\
\hline & Driver & $344(38.2)$ \\
\hline & Pillion rider & $224(24.9)$ \\
\hline \multirow[t]{6}{*}{ Victim's vehicle involved in accident $\left(n=736^{\#}\right)$} & Bicycle & $35(4.8)$ \\
\hline & Motorized two-wheeler & $393(53.4)$ \\
\hline & Motorized/manually driven three-wheeler & $106(14.4)$ \\
\hline & Motorized four-wheeler & $145(19.7)$ \\
\hline & Bus & $33(4.5)$ \\
\hline & Truck & $24(3.2)$ \\
\hline \multirow[t]{5}{*}{ Opposite vehicle with which collision took place $\left(n=750^{\varsigma}\right)$} & Motorized two-wheeler & $66(8.8)$ \\
\hline & Motorized/manually driven three-wheeler & $59(7.9)$ \\
\hline & Motorized four-wheeler & $295(39.3)$ \\
\hline & Bus & $205(27.3)$ \\
\hline & Truck & $125(16.7)$ \\
\hline \multirow[t]{4}{*}{ Sitting capacity of victim's vehicle $(n=900)$} & $1-2$ & $484(53.7)$ \\
\hline & $3-5$ & $155(17.2)$ \\
\hline & $6-10$ & $22(2.4)$ \\
\hline & $>11$ & $29(3.2)$ \\
\hline \multirow[t]{5}{*}{ Site of accident $(n=900)$} & Straight road & $504(56.0)$ \\
\hline & Crossing & $169(18.8)$ \\
\hline & Flyover & $121(13.4)$ \\
\hline & Wrong direction & $66(7.3)$ \\
\hline & U-turn & $40(4.5)$ \\
\hline \multirow[t]{4}{*}{ Time of accident $(n=900)$} & $6 \mathrm{PM}$ to $12 \mathrm{mid}$ night & $234(26.0)$ \\
\hline & Midnight to $6 \mathrm{AM}$ & $252(28.0)$ \\
\hline & $6 \mathrm{AM}$ to $12 \mathrm{PM}$ & $195(21.7)$ \\
\hline & 12 noon to $6 \mathrm{PM}$ & $219(24.3)$ \\
\hline \multirow[t]{3}{*}{ Perception regarding person responsible for accident $(n=900)$} & Self & $30(3.3)$ \\
\hline & Opposite driver & $768(85.4)$ \\
\hline & Road & $102(11.3)$ \\
\hline \multirow{2}{*}{$\begin{array}{l}\text { Use of helmet by driver/pillion rider of motorized } \\
\text { two-wheeler }(n=393)\end{array}$} & Yes & $249(63.3)$ \\
\hline & No & $144(36.7)$ \\
\hline \multirow{2}{*}{ Use of seat belt by driver/passenger of four-wheeler $(n=145)$} & Yes & $47(32.4)$ \\
\hline & No & $98(67.6)$ \\
\hline
\end{tabular}

*Victims who were travelling in bus/truck/car/three-wheeler at the time of accident, "Pedestrians were excluded, ${ }^{5}$ In 150 accidents, there was no collision with another vehicle from opposite direction; accident took place by sliding or collision with road divider

i.e., 497 (55.2\%) had planned to travel up to $25 \mathrm{~km}$. Out of 900 , majority of the participants, i.e., $530(58.8 \%)$ had taken $<6 \mathrm{~h}$ of sleep previous night, while $370(41.2 \%)$ had taken more than $6 \mathrm{~h}$ of sleep (data not shown).

\section{Discussion}

The present study was a hospital-based study carried out in the emergency department of a tertiary care trauma center where interviews of 900 RTI victims or their attendants were conducted using a pretested semi-structured interview schedule.

Males ( $84 \%$ ) outnumbered females $(16 \%)$ by a large margin. This finding was very much similar to several earlier studies, with males consisting of $74.4 \%-90 \%$ of accident victims. ${ }^{[6-13]}$ This is obvious due to the fact that more males are usually outdoor for work as compared to females. The age group mostly affected was 16-30 years (47.4\% participants). Other studies from various parts of India have also shown that majority of the victims belonged to $20-29$ or $20-30$ age group. ${ }^{[9-13]}$ The younger generation often have risk-taking behaviors, and this may explain the findings. Studies from Rwanda, Iran, and Nepal have validated this finding of male predominance and younger age among RTI victims. ${ }^{[14-16]}$

In the present study, $41.9 \%$ victims were occupants (passengers/pillion riders), followed by drivers $(38.2 \%)$ and pedestrians (19.9\%). Patil et al. reported a somewhat similar finding of $49.7 \%$ of victims being occupants, and $36.9 \%$ being drivers. ${ }^{[1]}$ Pedestrians have been reported in various studies to range from $13.4 \%-40 \%{ }^{[8,10,11,13,17]} \mathrm{A}$ study from Kenya reported that majority of RTI victims were pedestrians $(30.8 \%){ }^{[18]}$ However, another study from Africa showed similar finding to our study where motorized two-wheelers were most commonly 


\begin{tabular}{|c|c|c|}
\hline Factor-related to prehospital care & Category & Number of participants (\%) \\
\hline \multirow[t]{4}{*}{ First responder to offer help at accident site } & Passer-by & $360(40.0)$ \\
\hline & Co-rider/co-passenger & $279(31.0)$ \\
\hline & Police & $227(25.2)$ \\
\hline & Driver/rider of opposite vehicle with which collided & $34(3.8)$ \\
\hline \multirow[t]{5}{*}{ Vehicle used for transport to hospital } & Ambulance & $131(14.6)$ \\
\hline & PCR van* & $406(45.1)$ \\
\hline & Motorized two-wheeler (private/commercial) & $83(9.2)$ \\
\hline & Private motorized three-wheeler (private/commercial) & $206(22.9)$ \\
\hline & Private four-wheeler (private/commercial) & $74(8.2)$ \\
\hline \multirow[t]{2}{*}{ Time taken to reach hospital } & $\leq 30 \mathrm{~min}$ & $709(78.8)$ \\
\hline & $>30 \mathrm{~min}$ & $191(21.2)$ \\
\hline \multirow[t]{4}{*}{ Person who brought victim to hospital } & Co-rider/co-passenger & $256(28.4)$ \\
\hline & Driver/rider of opposite vehicle with which collided & $26(2.9)$ \\
\hline & Passer by & $205(22.8)$ \\
\hline & Police & $413(45.9)$ \\
\hline \multirow[t]{3}{*}{ Time taken by doctor to attend victim } & $\leq 5 \mathrm{~min}$ & $499(55.4)$ \\
\hline & $>5-<10 \mathrm{~min}$ & $302(33.6)$ \\
\hline & $>10 \mathrm{~min}$ & $99(11.0)$ \\
\hline
\end{tabular}

*PCR van: Police control room van

involved and pedestrians were involved in one-fifth cases. ${ }^{[19]}$ Victim's vehicle involved in majority of cases was a motorized two-wheeler (53.4\%) and the opposite colliding vehicle was a four-wheeler $(39.3 \%)$ in most cases. Pathak et al. reported that nearly $72 \%$ of RTIs involved motorized two-wheelers and most common opposite vehicle colliding were four wheelers. ${ }^{[9]}$ The current study also found that more than one-fourth of the cases among opposite colliding vehicles were buses. This is an important finding since most of these accidents will be severe due to higher impact.

In our study, the majority of RTIs happened between midnight to 6 A.M. (28\%) followed by 6 P.M. to midnight (26\%). This was slightly different from some earlier studies in which most accidents took place between late afternoon/evening and late night/midnight. ${ }^{[8,20,21]}$ Farooqui et al. and Mishra et al. had reported that maximum accidents took place in the daytime between afternoon to evening time. ${ }^{[7,17]}$ The higher proportion of accidents between midnight and morning in our study can be ascribed to the nightlife culture in bigger metropolitan cities like New Delhi and lack of traffic control systems during those hours which leads to increased risky behaviors, especially in the younger generation.

In the present study, $63.3 \%$ of the victims wore helmets at the time of accident. This was similar to two studies in which close to $65 \%$ victims wore helmets. ${ }^{[9,10]}$ We found that seat belts were used by only $32.4 \%$ victims. This was similar to previous studies..$^{[10,22]}$ This hints towards the huge need of proper implementation of road traffic regulations and awareness generation among the drivers and passengers riding vehicles. Behavioral change interventions will be needed to change people's perceptions and attitudes related to risk of RTIs and the physical, social, economic, and psychological consequences it can have on the victims lives.
Almost one-fifth of the drivers in the present study did not possess a driving license during the time of accident. This was very much consistent with previous studies, in which, $11 \%$ to $37.6 \%$ drivers did not possess a valid license. ${ }^{[11,22,23]}$ The proportion of victims not possessing a driving license in the present study, looks still higher for Delhi, considering the fact that it is the national capital and laws are supposed be more strictly implemented. It points toward the fact that it could be much lower in smaller cities and towns.

In majority (40\%) of the accident cases in the present study, first responders to offer help at accident site was an unknown passerby. We found that also, in most cases $(45.1 \%)$, police control room van transported victims to the hospital. More than $40 \%$ victims were carried to hospital in private vehicles, most commonly a motorized three-wheeler. Ambulance was used in only $14.6 \%$ of cases. All these findings suggest toward the gross inadequacies in providing prehospital care in India. Unawareness of people regarding how to call an ambulance, and tendency to avoid police procedures coupled with the fast-paced, busy life in Delhi could be the possible reasons behind these findings.

The strengths of the study were that all interviews were conducted face-to-face by a single interviewer, with minimal participant refusal. One limitation was that the present study might have underestimated the measurement of some of the factors associated with accidents because of willful suppression or misrepresentation of facts by the participants due to fear of medico-legal complications. Furthermore, since accident is an emergency, it is possible that some of the victims might have responded perfunctory, just to complete the interview. Another obvious limitation was that in case of unconscious victims, all the information provided by the attendant may have been fully conversant of relevant facts. 


\section{Conclusion}

Considering that high proportion of RTI victims were young drivers, school-based road safety awareness programs should be periodically conducted to decrease high-risk behaviors while driving. Focus should be directed to make use of safety measures such as helmet and seatbelt, especially among the youth. There is a huge need for development of better trauma system and trauma care services for RTI patients, especially prehospital care. An integrated approach geared toward better coordination between prehospital care and definitive care (in the hospital) through better availability of trained human resources (particularly on the job training and training of vehicle drivers in first aid), strengthening of ambulance service, infrastructural changes and better supply of logistics would be required for trauma care in the country. Bringing in newer legislations Strengthening of existing laws and ensuring their proper implementation for drunk driving, mobile phone use while driving and nonuse of helmets and seat belts is the need of the hour.

\section{Acknowledgment}

We would like to thank Dr. Dharampal Swami for his help in this study.

\section{Financial support and sponsorship}

Nil.

\section{Conflicts of interest}

There are no conflicts of interest.

\section{RefERENCES}

1. Accidental Deaths and Suicides in India 2015. National Crime Records Bureau. Ministry of Home Affairs. Available from: http://www.ncrb.nic. in/. [Last accessed on 2017 Apr 21].

2. Rai SK, Gupta A, Srivastava R, Bairwa M, Misra P, Kant S, et al. Decadal transition of adult mortality pattern at Ballabgarh HDSS: Evidence from verbal autopsy data. BMC Public Health 2015;15:781.

3. Jagnoor J, Suraweera W, Keay L, Ivers RQ, Thakur J, Jha P, et al. Unintentional injury mortality in India, 2005: Nationally representative mortality survey of 1.1 million homes. BMC Public Health 2012;12:487.

4. Ruikar M. National statistics of road traffic accidents in India. J Orthop Traumatol Rehabil 2013;6:1-6.

5. International Statistical Classification of Diseases and Related Health Problems, Tenth Revision. Vol. 1: Tabular List. Geneva: World Health Organization; 1992. Available from: http://www.who.int/classifications/ icd/ICD10Volume2_en_2010.pdf. [Last accessed on 2017 Apr 22].
6. Hsiao M, Malhotra A, Thakur JS, Sheth JK, Nathens AB, Dhingra N, et al. Road traffic injury mortality and its mechanisms in India: Nationally representative mortality survey of 1.1 million homes. BMJ Open 2013;3:e02621.

7. Mishra B, Sinha Mishra ND, Sukhla S, Sinha A. Epidemiological study of road traffic accident cases from western Nepal. Indian J Community Med 2010;35:115-21.

8. Dsouza C, Rao VV, Kumar A, Diaz E. Epidemiological trends of trauma in tertiary care centre in Dakshina Kannada district of Karnataka, India. J Clin Diagn Res 2014;8:66-8.

9. Pathak SM, Jindal AK, Verma AK, Mahen A. An epidemiological study of road traffic accident cases admitted in a tertiary care hospital. Med J Armed Forces India 2014;70:32-5.

10. Mahajan N, Aggarwal M, Raina S, Verma LR, Mazta SR, Gupta BP, et al. Pattern of non-fatal injuries in road traffic crashes in a hilly area: A study from Shimla, North India. Int J Crit Illn Inj Sci 2013;3:190-4.

11. Patil SS, Kakade R, Durgawale P, Kakade S. Pattern of road traffic injuries: A study from Western Maharashtra. Indian J Community Med 2008;33:56-7.

12. Singh R, Singh HK, Gupta SC, Kumar Y. Pattern, severity and circumtances of injuries sustained in road traffic accidents: A tertiary care hospital-based study. Indian J Community Med 2014;39:30-4.

13. Kanchan T, Kulkarni V, Bakkannavar SM, Kumar N, Unnikrishnan B. Analysis of fatal road traffic accidents in a coastal township of South India. J Forensic Leg Med 2012;19:448-51.

14. Patel A, Krebs E, Andrade L, Rulisa S, Vissoci JR, Staton CA, et al. The epidemiology of road traffic injury hotspots in Kigali, Rwanda from police data. BMC Public Health 2016;16:697.

15. Hamzeh B, Najafi F, Karamimatin B, Ahmadijouybari T, Salari A, Moradinazar M, et al. Epidemiology of traffic crash mortality in west of Iran in a 9 year period. Chin J Traumatol 2016;19:70-4.

16. Karkee R, Lee AH. Epidemiology of road traffic injuries in Nepal, 2001-2013: Systematic review and secondary data analysis. BMJ Open 2016;6:e010757.

17. Farooqui JM, Chavan KD, Bangal RS, Syed MM, Thacker PJ, Alam S, et al. Pattern of injury in fatal road traffic accidents in a rural area of Western Maharashtra, India. Australas Med J 2013;6:476-82.

18. Matheka DM, Kitonyi MN, Alkizim FO. Three-month pattern of road traffic injuries at a Kenyan level 4 hospital. Pan Afr Med J 2015;20:78.

19. Sango HA, Testa J, Meda N, Contrand B, Traoré MS, Staccini P, et al. Mortality and morbidity of Urban road traffic crashes in Africa: Capture-recapture estimates in Bamako, Mali, 2012. PLoS One 2016;11:e0149070.

20. Radjou AN, Balliga DK, Pal R, Mahajan P. Injury-related mortality audit in a regional trauma center at Puducherry, India. J Emerg Trauma Shock 2012;5:42-8.

21. Kiran ER, Saralaya KM, Vijaya K. Prospective study on road traffic accidents. J Punjab Acad Forensic Med Toxicol 2004;4:12-6.

22. Rastogi D, Meena S, Sharma V, Singh GK. Causality of injury and outcome in patients admitted in a major trauma center in North India Int J Crit Illn Inj Sci 2014;4:298-302.

23. Dandona R, Kumar GA, Dandona L. Risky behavior of drivers of motorized two wheeled vehicles in India. J Safety Res 2006;37:149-58. 